\title{
DEEP SEA DWELLERS: \\ Drexciya and the Sonic Third Space
}

[Received June $23^{\text {rd }}$ 2016; accepted August $30^{\text {th }} 2016$ - DOI: 10.21463/shima.10.2.08]

\section{Nettrice R. Gaskins}

$<$ nettrice@gmail.com>

\begin{abstract}
This article addresses the complex conceptual framework of Drexciya, an electronic music duo from Detroit who established an origin myth based on the Middle Passage, the route for ships carrying enslaved African people from one geographical location to another across the Atlantic Ocean. Whereas the origin myth of Plato's Atlantis ends in a permanent submersion into the sea, the world of Drexciya begins with the creation of an underwater country populated by the unborn children of pregnant African women thrown off of slave ships. Drexciya exists as a sonic third space characterised by embedded myths, the construction of culture and the invention of tradition. I will highlight the development of this sonic fiction that spans several decades, influencing many artists, musicians and scholars, by focusing on the Drexciyan concept of an intercultural, transnational network that shows the movement, migration, or scattering of people away from their homeland, and newly created spaces that transform identities and cultures. This article draws on obscure artist interviews and well-known sources about Drexciya, including essays by Kodwo Eshun and Ben Williams, while advancing the notion of non-physical, sonic islands that sit in spaces between the island and the ocean.
\end{abstract}

KEYWORDS: Drexciya, Black Atlantic, Middle Passage, electronic music, third space

\section{Introduction}

Myths reveal that the World, man, and life have a supernatural origin and history, and that this history is significant, precious, and exemplary. (Eliade, 1963: 19)

Origin myths purport to describe the creation of a natural or social world. Every origin mythology describes how a new reality came into existence. The story of Atlantis comes to us from Timaeus, a Socratic dialogue, written in about 360 BC by Athenian philosopher Plato. Atlantis, taking its name from Atlas, the god of navigation, can be interpreted as an allegory for the myth of the creation of a world with Athens, Greece at the center. Plato's account describes a seafaring civilisation that battled the Athenians, angered the gods and perished into the Atlantic Ocean. The Atlantis story, which describes the creation and destruction of an ideal state, extends to other stories, ruptures and a complete disintegration of one experience to create another (Smallwood, 2007: 122). One such story was based on the Middle Passage, the route for ships carrying enslaved African people from one geographical location to other places across the sea.

In his essay 'Black Secret Technology' Williams considers Drexciya, an origin myth and aural journey created by a Detroit-based electronic music duo of the same name. Drexciya, according to the duo, was an underwater country populated by the unborn children of 


\section{Gaskins: Deep Sea Dwellers - Drexciya}

pregnant African women thrown off of slave ships during the Middle Passage who had learned to breathe underwater in their mother's wombs (Williams, 2001: 168). The Middle Passage is a popular subject among artists, scholars and writers across the African Diaspora and the Black Atlantic (see Gilroy, 1992, for instance). Thus, Drexciya, a much lesser known a myth of origin (as well as soundscape that situates listeners in a liminal space between these experiences and representations), is a subject that will be further explored in this article.

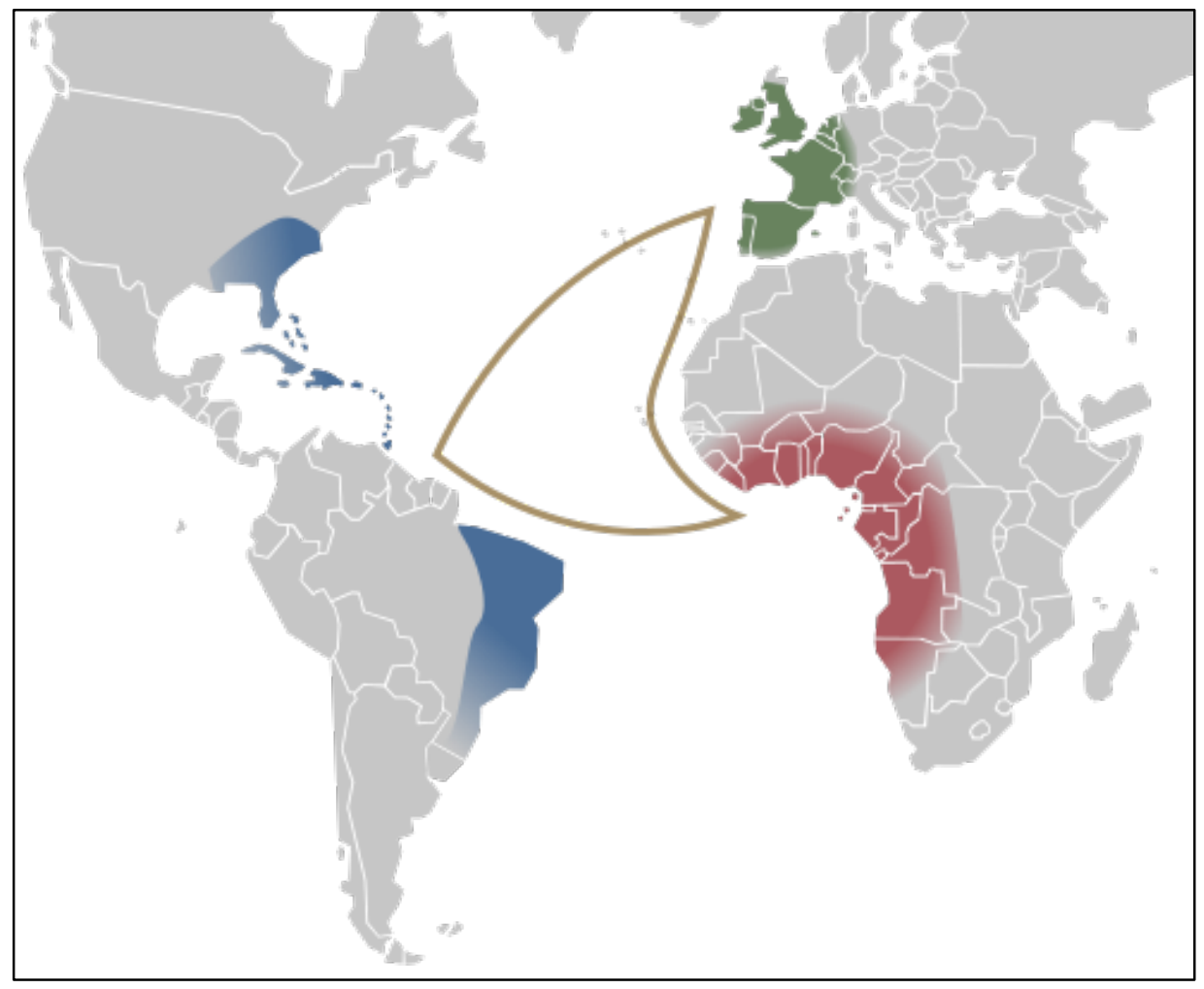

Figure 1 - The Atlantic Slave Trade and Middle Passage. Creative Commons SA 3.0. ${ }^{1}$

Unlike Plato's Atlantis tale that ended with the submersion of an island into the sea, Drexciya begins with the rupture of the Middle Passage and the subsequent submersion of survivors who created a new, albeit fictional, nation. Drexciya was never lost to us; it forever exists in channels that were created within the depths of a sonic universe. Kodwo Eshun noted that the Drexciyan myth, built partly on Paul Gilroy's The Black Atlantic: Modernity and Double Consciousness (1992) is used to highlight the influence of the slave trade on black identity and culture (Maloney, 2012: online). Gilroy's book identifies a hybrid culture that connects the continents of Africa, the Americas and Europe, resisting

${ }^{1}$ Triangular_trade.png: SémhurWorld_map_-_low_resolution.svg: Al MacDonald [1]/ twitter account @FiLT3Rderivative work: Jon C - Triangular_trade.pngWorld_map__low_resolution.svg: https://commons.wikimedia.org/w/index.php?curid=17827742 accessed 28th August 2016. 


\section{Gaskins: Deep Sea Dwellers - Drexciya}

the simple understanding Black Atlantic cultures as being marginal to or derived from dominant national cultures. Rather, the Black Atlantic is a modern political and cultural formation defined by a desire to transcend the structures of nation states. Drexciya, as members of a new generation of Black Atlantic artists in the 1990s, sat at the juncture between different genres and representations. Their project evokes Gilroy's image of a ship-a living, microcultural, micro-political system in motion - that was later replaced by Parliament-Funkadelic's or P-Funk's metaphysical mothership and, eventually, the TR-8o8 drum machine, an aural container that produced electronic bass sounds to simulate the talking drum, creating rhythms that were powerful enough to communicate across distances.

In Africa, thousands of years ago, high-tech nomads began to emerge from a dimensional jump-hole... To those that know, they have left their mark all over the world (including in) a subterranean city, deep on the ocean floor... where Africans were brought to when they were thrown off the slave ships. (Rennicks, 2005: online)

Recurring fictional characters, themes and ideas from a series of concept albums performed by P-Funk also inspired Drexciya. Kodwo Eshun called Drexciya "electronic music's most ambitious sonic fiction since Parliament's 1975-79 Mothership Connection cycle" (1998a: 19). The latter included Motor Booty Affair (1978), which continues a story in which the ocean is a realm where the life of Middle Passage survivors continues, and where the African Diaspora is united in rhythm and music. P-Funk mythology was based on a Black Atlantis, or a place where one can "dance underwater without getting wet." On the P-Funk song Deep, the citizens of Atlantis raise their home out of the sea. They sing, "We need to raise Atlantis from the bottom of the sea, dancing til we bring it to the top." With album releases such as Deep Sea Dweller (1992), Drexciya 2: Bubble Metropolis (1993), Drexciya 4: The Unknown Aquazone (1994), The Quest (1997) and Neptune's Lair (1999), there is little doubt of the impact of P-Funk mythology on Drexciya.

\section{The Quest and the Bubble Metropolis}

Each Drexciya EP - from '92's Deep Sea Dweller, through Bubble Metropolis, Molecular Enhancement, Aquatic Invasion, The Unknown Aquazone, The Journey Home and Return of Drexciya to '97's Uncharted - militarizes Parliament's 7os and Hendrix's 6os Atlantean aquatopias. (Eshun, 1998b: 83)

Drexciya is a sonic rupture that exists between geographies (ie Africa and the Americas) that transports listeners to a "bubble metropolis" where the ocean floor is home to the "webbed mutants" of the Black Atlantic. Drexciya's first album release, The Quest, included inner sleeve liner notes with a map that illustrates their origin mythology and is divided into four stages: The Slave Trade, Migration Route of Rural Blacks to Northern Cities, Techno Leaves Detroit, Spreads Worldwide, and The Journey Home (Future) (Figure 2). This map visualises the concept of an intercultural, transnational network by showing the movement, migration, or scattering of people away from their homeland, as well as the newly established bonds that transform identities and cultures. The Quest, as a manifesto for Black Atlantic transnational cultural construction, is deeply embedded in electronic music such as techno or electro and shows the cultural relevance of sound as a vehicle for self-determination. The Quest extended and materialised the Drexciya myth: Drexciyans were an evolved race of people, the music was their talking drum to battle forces seeking 
to remove them from existence, and liner notes served as a guide that explained the 'who, what and why' of the Drexciyan mission.

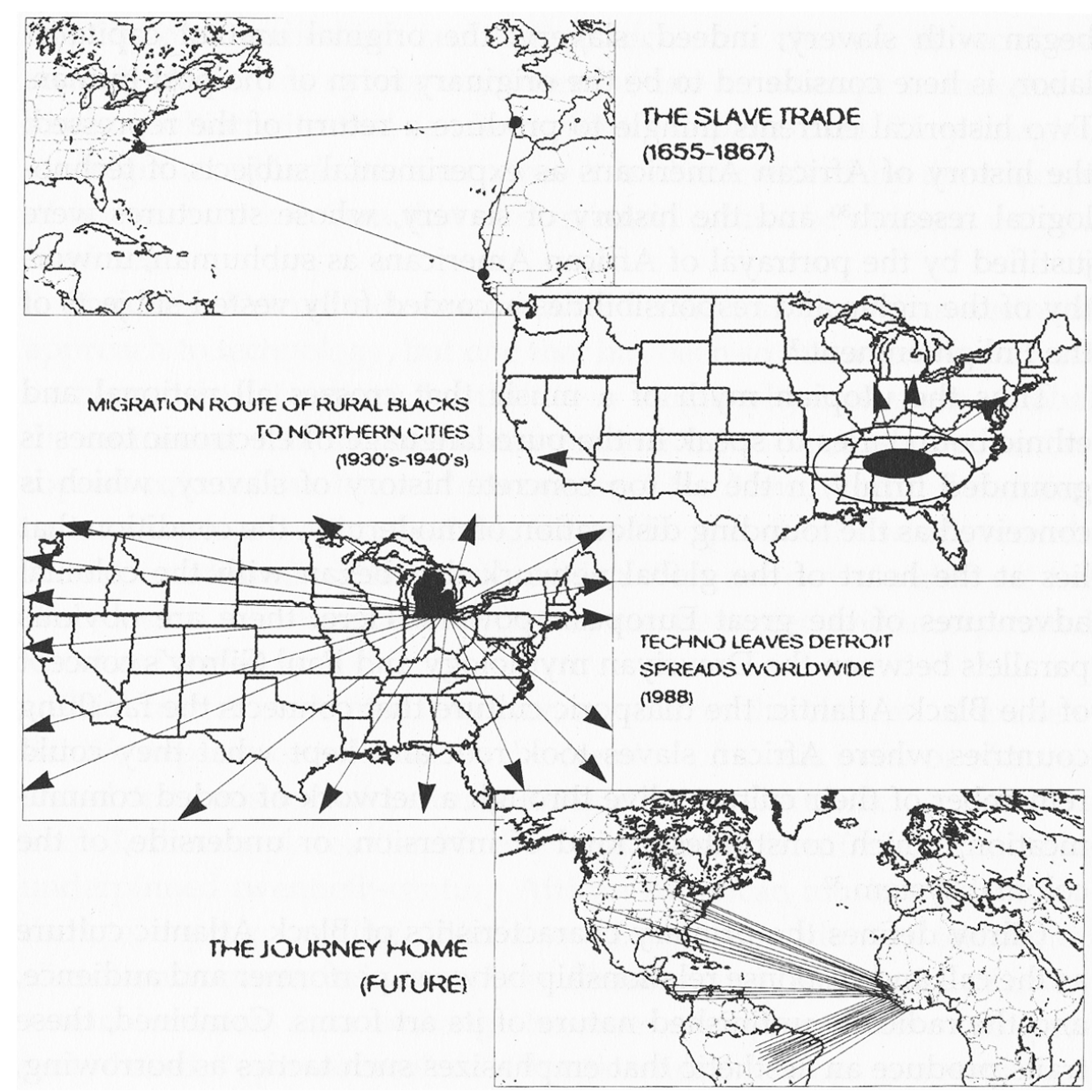

Figure 2 - The Quest liner notes by Drexciya. (Source: Ben Williams, Drexciya).

The transatlantic slave trade laid the foundation for modern capitalism, generating immense wealth for corporations in the Americas and Europe. The trade contributed to the industrialisation of the West and created a single Atlantic world that included Western Europe, Western Africa, the Caribbean islands and North and South America. Gilroy uses the image of a ship to represent authentic black culture, which is composed of many cultural exchanges since the slave trade has stifled blacks' ability to connect to a homeland. Additionally, this cultural exchange coincided with a commodity exchange that defined the transatlantic slave trade and, thus, black culture. Drexciya reimagined this development in The Quest. Learning to adapt to underwater life, the deep-sea dwelling Drexciyans, as the allegorical ancestors of Africans in the Americas, provide a model that privileges cultural hybridity. This hybridisation, according to Gilroy, is part of an ongoing process of travel and exchange across the Atlantic, in Europe and the New World. Thus, Drexciya and The Quest provides listeners with a vehicle to liberate African diasporic people who have survived the Middle Passage in such a way that explicates the shared 


\section{Gaskins: Deep Sea Dwellers - Drexciya}

experience of slavery and the transfer of knowledge that occurred as a result of the slave trade.

The Atlantic African diaspora was a consequence of the development and growth referred to above, spreading and embedding cultural knowledge across the Americas, including in the United States where, after Emancipation, more than six million African Americans from the rural South relocated to the cities of the North, Midwest and West after World War II. This second Great Migration was one of the stops in The Quest. One of the northern cities was Detroit where Drexciya was born. Detroit, once a major centre of industrial (automobile) manufacturing, began outsourcing its auto market overseas and replacing humans with machine labor by the late 196os. The city was a center for African American popular music, especially with the creation of the Motown sound, a mix of rhythm and blues, soul, gospel, and funk. Motown attracted songwriters such as George Clinton who would eventually helm Parliament-Funkadelic. Derrick May described techno music as "George Clinton and Kraftwerk caught in an elevator, with only a sequencer to keep them company" (1988, sleeve notes to Techno! The New Dance Sound of Detroit). Detroit techno artists used science fiction imagery to envision a transformed society; the sound generated by the meeting of funk and futurism. Although Drexciya was formed in the same city as Juan Atkins, Derrick May, and other techno pioneers Drexciya member James Stinson resisted the connection to Detroit techno and eventually moved to Atlanta, Georgia (Drexciya Research Lab, 2006: online).

Stinson saw Drexciya as a whole different plane of reality, as a journey or quest to be freely interpreted by listeners. The duo sought to transcend labels but their music remained grounded in black music technology. The point was not to disguise what they were doing but to create new territory in electronic music. Drexciya produced music that flowed freely like the water they referenced endlessly in their track titles. A rare interview with Stinson provides more insight into Drexciyan mythology, including the story of the "Seven Storms" or seven albums produced in quick succession in the early noughties. When asked what the duo's theme was, Stinson said, it's "an infinite journey through inner-space within (to) find the beauty that is inside and bring it out" (Lardossan, 2002: online).

In The Quest we hear repetition in the looping, polyrhythmic patterns of the Roland TR808 , an electronic drum machine that produces extremely low-frequency sounds. We can hear the call and response interactions of black music technology such as the remixing of earlier music styles and genres with technology to represent the duo's strategy to create an alternative world:

This is Drexciyan Cruiser Control, Bubble One, to Lardossen Cruiser 8-203X, please decrease your speed to 1.788.4 kilobahn, thank you. Lardossen Cruiser 8-203X, please use extra caution as you pass the aqua construction site on the side of the aquabahn. I repeat, proceed with caution. (Bubble Metropolis sleeve notes, 1993)

The Middle Passage made the Atlantic a watery grave for millions of Africans forced to leave the continent. However, the survivors' descendants created alternative narrative spaces, moving the past forward in time to the African continent. The final leg of The Quest's voyage is The Journey Home (Future)', with multiple routes leading out of the Americas to Africa. Along the way, we encounter "wave jumpers" and "deep sea dwellers" that are the initial locators of the underwater island to which we travel as passengers (listeners) on a sonic Lardossen Cruiser. The track listing on the Drexciya 2: Bubble 


\section{Gaskins: Deep Sea Dwellers - Drexciya}

Metropolis EP should be read as a journey into Drexciya itself. The record begins with 'Aqua Worm Hole', then we arrive at 'Positron Island', 'Bubble Metropolis', 'Danger Bay' and, finally, we are welcomed to the sonic world of Drexciya itself.

Early Detroit techno producers employed science fiction or futuristic imagery to articulate their visions of a transformed society. Unlike other variants, Detroit techno more directly works at the junction of funk and futurism (Shallcross, 1997: 21). By the late 1980s, techno music had spread from the Midwestern United States to the southern states and outside of the country as far as Great Britain and throughout Africa. Drexciya's journey to Africa in the future was, in a sense, prophetic. You can hear Drexciya's influence on Sierra Leonean Lamin Fofana's EP Another World (2015). Fofana channels the subversive power of Drexciya's invented world in 'Lampedusa', a song title that references Italy's southernmost island seventy miles away from Tunisia. Between 2013 and 2015, several hundred African migrants died in route to Lampedusa, including in a ship that burned and sank off the coast. Fofana's music conveys a feeling of being adrift at sea somewhere between catastrophe and paradise (see Sherburne, 2015). This sense of between-ness, of existing neither here or there is Drexciya's story. Another World and Drexciya's Bubble Metropolis provide an oceanic soundscape as a metaphor for eternity, circumstance, and basic survival.

\section{The Oceanic Island Life of Drexciya}

Water is life. Life started on this planet and other planets due to water. It is the cutting edge of creativity and innovation. You have billions of different species in the seas, oceans, lakes ponds and streams across the world. Millions of species still have not been discovered by man so is that the cutting edge of creativity or what? We approach our music the same way. (Osselaer, cited in Drexciya Research Lab, 2005: online)

As much of the ocean has yet to be explored by humans it is a good place for artists to imagine alternate worlds and realities, which is evident in Drexciya's numerous titles. Water is the main theme throughout the music of Drexciya. Water also gives birth and provides passages to islands, some big or small, and others that are purely imaginary. The fictional islands of Drexciya, surrounded by the Atlantic Ocean, are networked through water. For the musicians and fans of their music, Drexciya immerses listeners in another dimension between the oceanic and island worlds. There are a few places of convergence between Atlantis, the legendary lost island subcontinent and Drexciya, the imaginary utopia for submerged Africans escaping slavery. While one (Atlantis) protected the Athenians from conflict the other was a form of escapism from oppression. Radford has contended that:

As propaganda, the Atlantis legend is more about the heroic Athens than a sunken civilization; if Atlantis really existed today and was found, its residents would probably try to kill and enslave us all. (2014: online)

Atlantis is often idealised as an advanced, utopian society holding wisdom that could bring world peace. However, for some, the Atlanteans were a technologically advanced society intent on world domination by force. Unlike Atlantis, Drexciya's origins begin with the forcible removal of people who, after a time, evolve into "wave-jumpers" or stingray and barracuda "battalions" who launch aquatic and sonic invasions against oppressors who 


\section{Gaskins: Deep Sea Dwellers - Drexciya}

control the mainstream airwaves. In spite of what happens in the atmosphere above the ocean, there is peace among the various species in the underwater world where all beings live as one. As Stinson has asserted:

Some of the things of slavery will tell more when the time comes. Stay tuned! I can only tell you a little bit now. After the storm is over I will tell the story. What I can tell you is that in Africa we have a dimensional jump hole. (Drexciya Research Lab, nd: online)

Drexciya's underwater paradise developed into a geopolitical subcontinent mapped through cartographic track titles. The double CD and record compilation The Quest offers up 'Danger Bay', one of the many island locations in Drexciya. The meaning of the song is open to debate; perhaps the danger comes from Doctor Blowfin, an ever present and extremely ambiguous character with a water cruiser. 'Dead Mans Reef is built around a looping keyboard riff that ends on a reef of bass (Rennicks, 2006: online). The title 'Vampire Island' could be read as another location to flesh out the Drexciyan world. 'Positron Island' references the Island of Doctor Positron, a location from the Marvel comic universe. Positron Island is a volcano located in the Pacific Ocean, which was used as the Doctor's headquarters. Positron was the alias of Dr. Max Brashear, a scientist who sought to open a portal called the Neutral Zone or Exo-Space that was found to exist between realities, or where negative and positive matter coexists (Ewing, 2015).

We can imagine Drexciya as the aquazone that surrounds an isolated archipelago somewhere in the Black Atlantic, with dimensional portals to Africa, North America, Europe and beyond Earth. These oceanic islands of music technology are separated from our physical reality. Drexciya's fictionalised frequencies exist in a dimension beyond the known, providing a passage for a dispersed people, connecting them to a homeland. This portal allows speedy travel between sonic coordinates. Other tracks such as 'Drexciyan R.E.S.T. Principle' further explore this development, as explained by Drexciya Research Lab:

In Africa, thousands of years ago, high tech nomads began to emerge from a dimensional jump-hole... To those that know, they have left their mark all over the world (including in a subterranean city, deep on the ocean floor). For the Drexciyans are never idle, their principle has always been Research, Experimentation, Science, and Technology, from Neptune's time to today. (Drexciya Research Lab, 2005: online)

The R.E.S.T. principle provides clues to all possible environments where Drexciyans can survive, from the depths of the Atlantic, to oceanic islands, or even outer space. James Stinson talked about extraterrestrial storms hitting Earth, which may explain the themes and titles on Harnessing the Storm. These ideas are all generated from the same source, for a primary purpose that comes from within the origin mythology of the Drexciyan universe. Not simply about a journey back to Africa, the duo's aim was something far more universal, a journey, which leads us as listeners to a place of self-discovery, no matter where we happen to live. Drexciyan lore is always at the threshold of reality, existing between previous ways of structuring identities, time, space, or networks, and a new way of life. It's a life that is meaningful but not always popular or fully understood by a mainstream audience. 


\section{Gaskins: Deep Sea Dwellers - Drexciya}

Life is an island in an ocean of solitude and seclusion. Life is an island, rocks are its desires, trees its dreams, and flowers its loneliness, and it is in the middle of an ocean of solitude and seclusion. (Gibran, 1976: 66

There is another way to look at the oceanic island concept of Drexciya, through the experiences and desires of an artist who intentionally removes himself from the mainstream way of life in order to create. While water provides the peaceful, isolated space Drexciyans need in order to research, experiment, and play with different ideas, the creations that emerge manifest in many environments. Stinson talks about his isolation from commercial electronic music, as well as from other individuals, groups, and labels attributed to Detroit techno. Stinson says that his (Atlantis-like) "cave" in Atlanta where he regenerates after an album is produced and released (Lardossan 2002). In isolation, he does not to look at what is going on in the music world, which he describes as toxic to his process. Thus, the island life of Drexciya becomes a metaphor for the seclusion of a nomad (Stinson) who finds inner peace in a comic book-like water world of his own creation.

\section{Drexciyan Hybridity and the Sonic Third Space}

It has been noted that Drexciya's method of production was secluded or disconnected from other techno and electro scenes (Ivers, 2012: online). Their sound carried the foundations of early techno and electro-funk as well as the ocean mythologies of Atlantis, and ancestral spirits in Africa. Note the similarities between Drexciya's "Darthouven Fish Men" and the amphibious, fish-like Nommo hybrids from outer space worshipped by the Dogon of Mali, for instance, both of whom require watery environments in which to live (Van Beek, 1991). Drexicya is what post-colonial scholar and theorist Homi Bhabha (1994) would refer to as a third space of enunciation or expression in which cultural systems are constructed (which includes embedded myths, the construction of culture and the invention of tradition). Bhabha's Third Space theory explains the uniqueness of people or contexts as hybrids.

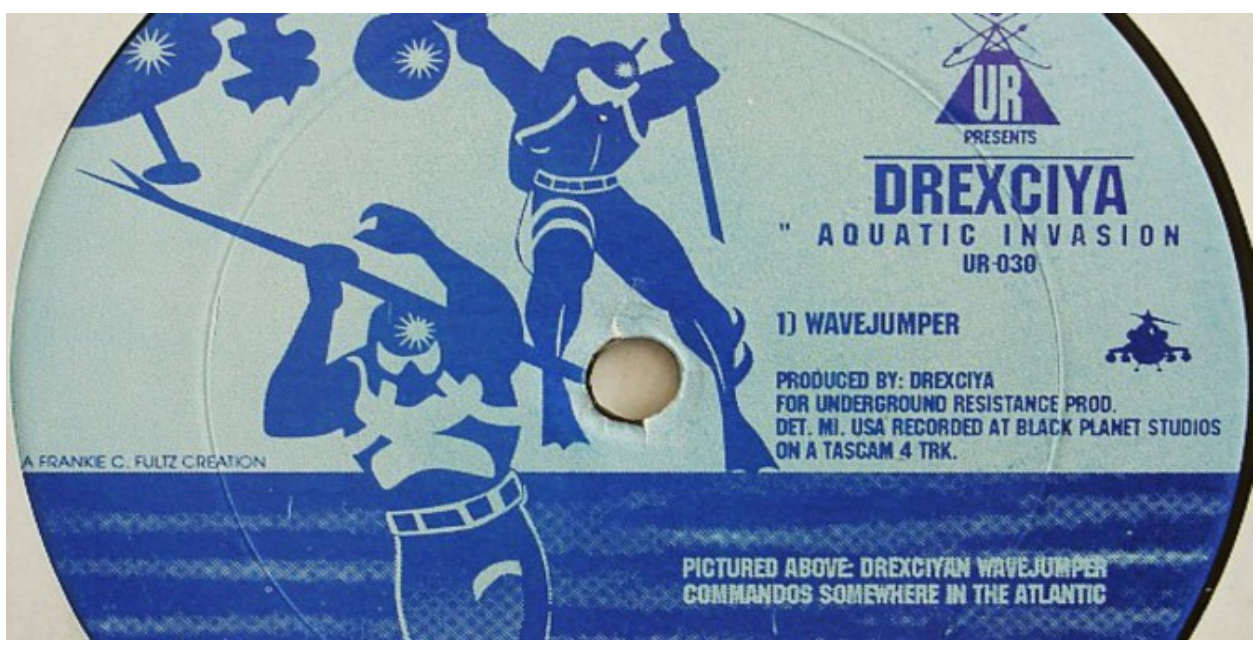

Figure 3 - "Drexciyan Wavejumper Commandos Somewhere in the Atlantic." (Detail From Drexciya record label.) 


\section{Gaskins: Deep Sea Dwellers - Drexciya}

Various scholars have referred to cultural and ethnic interactions and exchanges that draw on notions of translation and negotiation that comes into being when cultures and identities meet and blend, thereby challenging and displacing "our sense of the historical identity of culture" (Hanna, 2015: 20-21). Bhabha has identified that:

It becomes crucial to distinguish between the semblance and similitude of the symbols across diverse cultural experiences - literature, art, music, ritual, life, death - and the social specificity of each of these productions of meaning as they circulate as signs within specific contextual locations and social systems of value. The transnational dimension of cultural transformation - migration, diaspora, displacement, relocation - makes the process of cultural translation a complex form of signification. (1994: 247)

The notion of a Third Space can also be seen in Julie Dash's Daughters of the Dust, a 1991 film set in the early zoth Century among a Gullah community who live at Ibo Landing on St. Simons Island. Centuries before, the Peazant family's ancestors where brought to the island as enslaved African people. Over time, they developed their own language and culture in relative isolation from other areas and groups. Similarly, the Wakandans of Marvel comic lore come from a fictional East African nation with the most advanced technology in the universe (see Marvel Universe, nd: online). Isolated from the rest of the world, Wakanda developed its own organic technology that came from their agricultural needs (Harding, 2016: online). Singer Beyoncé's song and music video, "Formation," as well as scenes from her audio-visual album Lemonade features trap music from post-Katrina New Orleans, a successor to post-industrial Detroit techno. In all of these instances similar themes emerge such as African diasporic traditions, hybridity, techno-cultural creativity and innovation, and a passage into the dimensional jump-hole described by Stinson, which is like the Kalunga line, a watery boundary between the world of the living and the dead in religious traditions of the African Congo. The word Kalunga is Kikongo for "threshold between worlds" (Thompson, 1984). The Kalunga line with its cross at the centre is often associated with bodies of water, with the Atlantic Ocean being prominent (Figure 4). As I have identified elsewhere:

In folklore and mythology, the crossroads represents a location "between the worlds" and, as such, a site where supernatural spirits can be contacted and paranormal events can take place. Symbolically, it can mean a locality where two realms - Nseke and Mpemba - touch and, therefore, it represents liminality, or a place literally "neither here nor there". (Gaskins, 2016:3)

These examples mentioned here provide diverse cultural narratives about real and imagined people or beings that live on either side of the dimensional jump-hole. Fictional Wakanda is isolated from the rest of the world like Drexciya, occupying the thresholds between the Earth's natural elements, sound and hybridity, Africa and the universe. Long after the trans-Atlantic slave trade ended ideas about this between-ness have proliferated. Through electronic music, Drexciya reveals the third space through a sonic engagement with water, island life, futurity, and the transnational dimension of transformation. Drexciya unseats the language and textuality of the Middle Passage as a narrative that reconceptualises Atlantis as an Afro-futuristic space. 


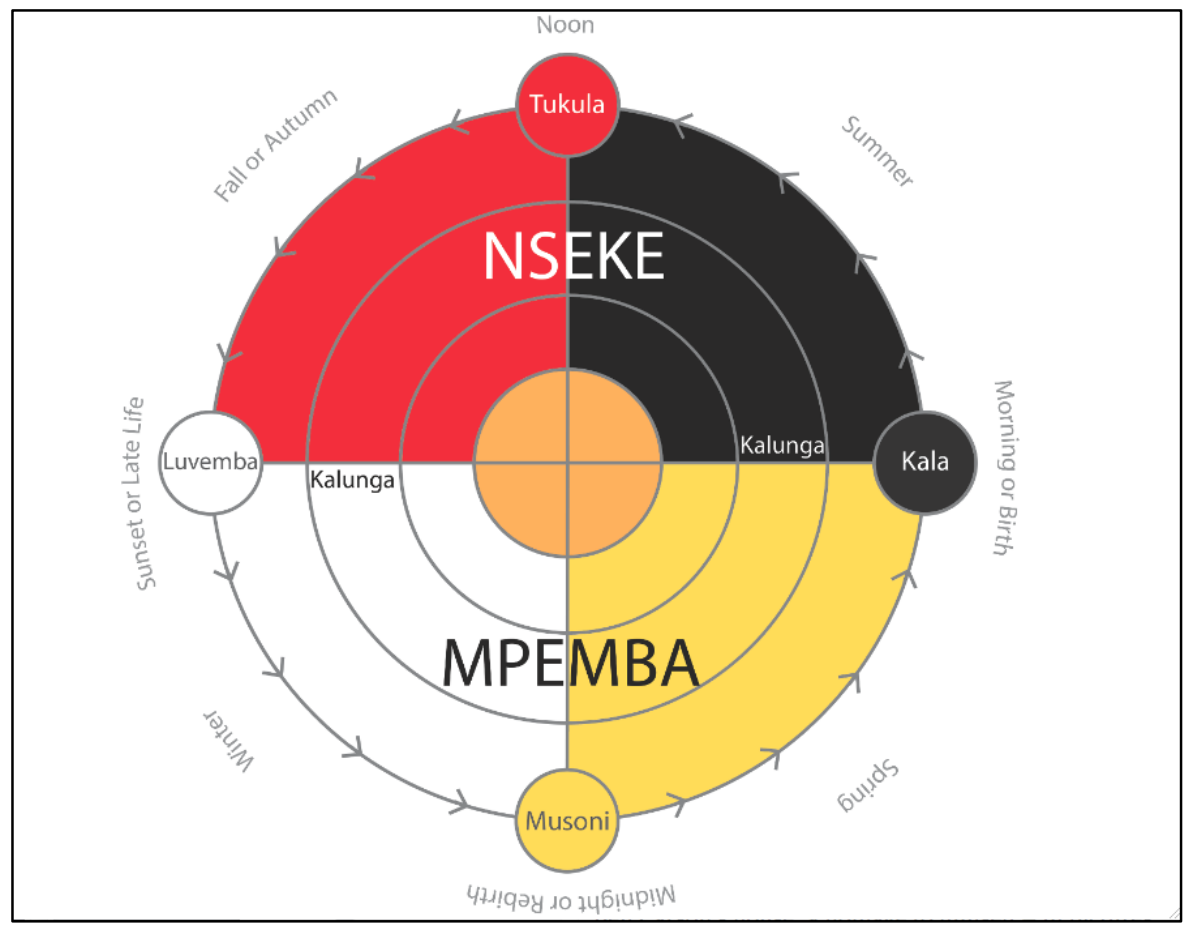

Figure 4 - Cosmogram with Kalunga line (center) - by Nettrice Gaskins.

The realms of Nseke (the upper, physical world) and Mpemba (the underworld) in the cosmogram motif provide a visual for the Drexciyan jump-hole. The bottom half is also referred to as Kalunga and this mythical underworld comes to life through Drexciya's music - dispersing into the airwaves, distorted by machines and electrified with funk.

For Ellen Gallagher the Drexciyan origin myth becomes a two-dimensional visual space for exploring signification and identity in art. As she has identified:

The voyage itself becomes a kind of origin myth that I'm referring to. So for me, it's the Middle Passage itself, rather than some version of an origin myth based on a Mother Africa. It's the passage itself. It's the concept of mutability that, I think, is the kind of origin myth that I'm referring to here, both in these drawings, literally, and more distantly in the paintings. (Art21, 2005: online.)

For Gallagher, the sea serves as a site of transformation between cultures and the inbetween or liminal state of otherworldly beings in space and time. Gallagher creates worlds through her visual images, animations and video projections, merging hybrid organisms with the biological ecosystems of the Atlantic Ocean. She pieces together imagery with painted surfaces and patterns to explore the split nature of cultural identity. Intricate, incised watercolor-based drawings from her ongoing Watery Ecstatic series depicts the natural environment of the sea. It is only when peering closely that one can see hybrid sea creatures with colorful hair and brown faces. Through collage Gallagher explores repetition with techniques that employ what scholar James A. Snead (1984) refers to as the "cut". This cut or disruption in a composition - as a transformation through 


\section{Gaskins: Deep Sea Dwellers - Drexciya}

sound and signification - enables artists such as Gallagher and Drexciya to piece together the fragments of the past to create alternate spaces for cultural hybrids to thrive.

\section{Conclusion}

Metaphors for the ocean and its islands are helpful ways to understand the music of Drexciya. However, that is just the beginning of the journey into myriad spatialities where the themes re-imagine many cultural, scientific and technological concepts. The dimensional jump-hole to Africa is our portal between the known worlds, into a hybrid reality or techno-cultural aquazone. This threshold brings us the Dogon's Nommo as well as Drexciya's "Water Walker". Drexciya is mysterious and isolated from the rest of the world in perpetuity due to the untimely death of James Stinson - at times emerging under names such as Dopplereffekt, Transllusion and The Other People's Place. The music takes us on a quest, from 'Deep Sea Dweller', which signals Atlantis, to 'Bubble Metropolis', which gives form to the Drexciyan world. Later, the duo explored Mars ('Red Hills of Lardossa') and Grava 4, an album that refers to grava theory, which is a single, continuous, super-field that contains and mediates all energy, mass, space and time in the entire universe. We adapt to these environments using 'Molecular Enhancement', and continue to the 'Unknown Aquazone' until 'The Journey Home', the nature of which is largely spiritual.

The Drexciyan sound is the portal to the realisation of a third space that represents a fusion of a physical first space and a remote second space; at times transcending geographies into a networked place that can be experienced by multiple listeners, across great distances. Drexciya's themes and cultural references cross over into other artists' projects, directly or indirectly, finding commonality the hybrid space that exists between worlds, in the watery boundary between the world of the living and the transformed. This threshold draws on modern African cultural ethos, technology, and artistic actuation by creating self-determined, representational worlds. In discourse of dissent, this is a place where the oppressed plot their liberation, where stolen or abandoned migrants survive adverse conditions. The sonic third space in the Drexicyan universe is a transport for the souls of survivors traveling back to Africa, re-entering the world of the living as beings that can survive deep in the depths of the ocean, on land, or wherever they chose to go.

\section{BIBLIOGRAPHY}

Art21 (2005) 'Ellen Gallagher: Characters, Myths, and Stories', Art21 Magazine - online at: http://www.art21.org/texts/ellen-gallagher/interview-ellen-gallagher-characters-mythsand-stories - accessed 27th August 2016

BBC Radio 4 (2007) Who Likes Techno? (first broadcast on 2nd October)

Bhabha, H (1994) The Location of Culture, London: Routledge

Drexciya Research Lab (nd) 'Don't Be Afraid of Evolution', online: http://www.freewebs.com/drexciyaresearchlab/drexciya19921999.htm - accessed 27th 2016

Drexciya Research Lab (2006) 'The Quest', Drexciya Research Lab 


\section{Gaskins: Deep Sea Dwellers - Drexciya}

Eliade, M (1963) Myth and Reality (translated Trask, W), New York: Harper \& Row

Eshun, K (1998a) 'Drexciya: Fear of a Wet Planet', The Wire nı67: 19-20, archived online at: http://afrofuturistaffair.tumblr.com/post/50385210621/drexciya-fear-of-a-wet-planet-bykodwo-eshun-the - accessed 2oth April 2016 Books

(1998b) More Brilliant Than The Sun: Adventures in Sonic Fiction, London: Quartet

Ewing, A (2015) 'We Are From Beyond,' Marvel's Captain America and the Mighty Avengers vi n5

Gaskins, N (2016) 'The African Cosmogram Matrix in Contemporary Art and Culture', Black Theology v14: 1-15

Gibran, K (1976) Mirrors of the Soul, New York: Carol Publishing Group

Gilroy, P (1992) The Black Atlantic: Modernity and Double Consciousness, Cambridge: Harvard University Press

Hanna, H (2015) Women Framing Hair: Serial Strategies in Contemporary Art, London: Cambridge Scholars Publishing

Harding, W (2016) “'Black Panther" has the coolest tech in the Marvel Universe', Popular Science 1oth May, online: http://www.popsci.com/black-panther-marvel-civil-wartechnology-wakanda 10 - accessed 2oth June

Ivers, B (2012) 'Deep Inside: Drexciya 'Journey of the Deep Sea Dweller II', XLR8R, online: https://www.xlr8r.com/features/2012/o6/deep-inside-drexciya-journey-of-the-deep-seadweller-ii - accessed 27th August 2016

Lardossan (2002) 'Drexciya Interview', online: https://www.youtube.com/watch?v=CLoZho4HC8 - accessed 27th August 2016

Maloney, P (2012) 'Interview with Kodwo Eshun of the Otolith Group', Art Practical 15th February, online at: http://www.artpractical.com/column/interview_with_kodwo_eshun accessed 27th August 2016

Marvel Universe Wiki (nd) 'Wakanda', online: http://marvel.com/universe/Wakanda accessed 27th August

Osselaer, J (2002) 'Drexciya: Twenty thousand leagues under the sea', Techno Tourist February, online at:

http://web.archive.org/web/20051216004847/http://technotourist.org/modules.php?op=m odload\&name=Sections\&file=index\&req=viewarticle\&artid=15 - accessed 28th August

Radford, B (2014) “Lost' City of Atlantis: Fact \& Fable', Live Science 31st October, online: http://www.livescience.com/23217-lost-city-of-atlantis.html - accessed 27th August 2016

Rennicks, S (2005) 'Grava 4', Drexciya Research Lab, 29th September: online at: Drexciyaresearchlab.blogspot.oe/2005/o9/grava-4.html - accessed 27th August 2016 


\section{Gaskins: Deep Sea Dwellers - Drexciya}

---- (2006) 'DRL F.A.Q.', Drexciya Research Lab: online at: http://drexciyaresearchlab.webs.com - accessed 2oth September 2016

Shallcross, M (1997) 'From Detroit To Deep Space', The Wire n161: 21

Sherburne, P (2015) 'Drexciya, Lamin Fofana, and What Techno Can Teach Us About the Migrant Crisis' Pitchfork 11th August, online: http://pitchfork.com/thepitch/863-drexciyalamin-fofana-and-what-techno-can-teach-us-about-the-migrant-crisis/ - accessed 27th August 2016

Smallwood, S.E (2007) Saltwater Slavery: A Middle Passage from Africa to American Diaspora, Cambridge: Harvard University Press

Snead, J.A (1984) 'Repetition as a figure of black culture,' in Gates, H.L (ed) Black Literature and Literary Theory, New York: Methuen \& Co Ltd: 59-80

Stephen (2005) 'Grava 4', Drexciya Research Lab 29th September: http://drexciyaresearchlab.blogspot.jp/2005/o9/grava-4.html - accessed 27th August

Thompson, R.F (1984) Flash of the Spirit: African and Afro-American Art and Philosophy, New York: Vintage Books

Van Beek, W.E.A (1991) 'Dogon Restudied: A Field Evaluation of the Work of Marcel Griaule', Current Anthropology n32: 139-167

Williams, B (2001) 'Black Secret Technology: Detroit Techno and the Information Age' in Nelson, A, Tu T.L.N and Headlam Hines, A (eds) Technicolor: Race, Technology \& Everyday Life, New York: New York University Press: 154-176

\section{DISCOGRAPHY}

Drexciya (1992) Deep Sea Dweller (EP, Shockwave)

----- (1993) Drexciya 2: Bubble Metropolis (EP, Underground Resistance)

---- (1994) Drexciya 4: The Unknown Aquazone (EP, Submerge)

----- (1997) The Quest (album, Submerge)

----- (1999) Neptune's Lair (album, 1999)

---- (200o) Grava 4 (album, Clone)

Lamin Fofana (2015) Another World (EP, self-released)

Parliament (1978) Motor Booty Affair (album, Casablanca Records)

Various Artists (1988) Techno! The New Dance Sound of Detroit (album, 10 Records) 